\title{
Synthesis, Electronic and Optical Properties of Cobalt(II) Dithiocarbamate Fluorescent Nanowires for Optoelectronic Devices
}

\author{
Sanjeev K. Ujjain ${ }^{1}$, Preety Ahuja ${ }^{1}$, Raj K. Sharma ${ }^{1} \&$ Gurmeet Singh ${ }^{1}$ \\ ${ }^{1}$ Department of Chemistry, University of Delhi, Delhi-110007, India \\ Correspondence: Raj K. Sharma, Department of Chemistry, University of Delhi, Delhi-110007, India. E-mail: \\ drrajksharma@yahoo.co.in; rajksharma@chemistry.du.ac.in
}

\author{
Received: December 15, 2014 Accepted: December 30, 2015 Online Published: February 3, 2015 \\ doi:10.5539/ijc.v7n1p69 \\ URL: http://dx.doi.org/10.5539/ijc.v7n1p69
}

\begin{abstract}
Schiff base containing symmetric bis-dithiocarbamate ligand $\mathrm{Na}_{2}$ [dtc-SB-dtc] ( $\mathrm{SB}=\mathrm{Bi}$-Schiff base Phenylene diamine) is synthesized and metallated with $\mathrm{Co}(\mathrm{II}) \mathrm{Cl}_{2} \cdot 6 \mathrm{H}_{2} \mathrm{O}$ to form $\left[\mathrm{Co} \text { (dtc-SB-dtc) } 2 \mathrm{H}_{2} \mathrm{O}\right]_{n} \mathrm{Co}$ (dtc-SB) infinite coordination polymer (ICP) nanowires [Co(dtc-SB) NWs]. Pair of Satellites in X-ray photoelectron spectroscopy (XPS) spectrum of Co $2 \mathrm{p}$ confirm the formation of hexa-coordinated Co(II). Presence of hyperfine pattern in low temperature EPR spectrum is due to the splitting of octahedral ground state ${ }^{4} \mathrm{~T}_{1}$ for $\mathrm{Co}(\mathrm{II})$. Introduction of a rigid, non-planar, four membered dtc Cobalt chelating ring in coordination polymer assisted in reduction of photoinduced electron transfer (PET) process to yield high fluorescence. Prepared Co(dtc-SB) NWs are highly resistive however after suitable doping, exhibit $\mathrm{p}$ and $\mathrm{n}$ type conductivity. Temperature dependent conductivity results of different doping concentrations in NWs reflect activated type conduction with two different activation energies. UV-Visible absorption spectra show decrement in optical gap whereas emission spectra demonstrate quenching after $\mathrm{p}$ and $\mathrm{n}$ doping. Efficient quenching of emission indicates energy transfer between dopant ions and NWs.
\end{abstract}

Keywords: Cobalt(II) coordination polymer, Bis-dithiocarbamate Schiff base phenylenediamine $\left(\mathrm{Na}_{2}\right.$ [dtc-SB-dtc]), optical absorption \& emission, conductivity

\section{Introduction}

Infinite Coordination polymers (ICPs) represent an area of growing interest in chemistry and materials science, owing to their potential application in drug delivery agent (Rieter, Pott, Taylor, \& Lin, 2008), encapsulating matrices (Nishiyabu, Aime, Gondo, Noguchi, \& Kimizuka, 2009), contrast agents (Taylor, Jin, \& Lin, 2008), catalysis (Park, Jang, Son, \& Sweigart, 2006), gas sorption (Tanaka et al., 2010), light harvesting (Zhang, Chen, \& Loh, 2009), electronic and sensing devices (Coronado, Mascaros, Capilla, Martinez, \& Pardo-Ibanez, 2007; Imaz et al., 2008; Rieter, Taylor, \& Lin, 2007; Cho, Lee, Lee, \& Oh, 2009). ICPs can be either highly crystalline structures, known as metal-organic frameworks (MOFs) (Oh, \& Mirkin, 2005; Jeon, Heo, \& Mirkin, 2007; Heo, Jeon, \& Mirkin, 2007; Lu, Chui, Ng, \& Che, 2008; Zhao et al., 2011) or amorphous nano/micro particles (Jeon, Armatas, Heo, Kanatzidis, \& Mirkin, 2008). Metal ions in ICPs bridged with organic ligands establish coupling between conduction electrons ( $\pi$ electrons) and localized magnetic moments (d spins) through $\pi-\mathrm{d}$ interaction. These unique interactions give rise to multifunctional molecular materials with optical properties, electronic conductivity, magnetism and numerous others. Recently, a great attention is given to designed nanoscale ICPs with different morphologies such as spheres (Sun, Dong, \& Wang, 2005; Champness, 2009; Imaz, Hernando, Molina, \& Maspoch, 2009), cubes (Jung, \& Oh, 2008), rods (Farha et al. 2009; Rieter, Taylor, An, Lin, \& Lin, 2006), wheels ( $\mathrm{Lu}$, Chui, $\mathrm{Ng}, \&$ Che, 2008) and nanofibres (Imaz, Martínez, Saletra, Amabilino, \& Maspoch, 2009) as they can be easily dispersed in many solvents and exhibit size/shape dependent properties. In particular, nanoscale 0-D and 1-D ICPs, integrated with optical and electrical properties has potential applications in molecular optoelectronics. The tetrathiafulvalene (TTF) derivatives are mainly used for synthesizing conducting ICPs (Bryce, 1991). TTFs are organic $\pi$-electron donor compounds with organylthio groups as chelating sites (Bryce, 1995). Due to the tedious synthetic procedure and hazardous nature, TTFs could not be extended to practical applications (Mueller, \& Ueba,1995). Developing new ligands with synthesis flexibility, low cost, three dimensional stacking capability along with excellent thermal stability and favourable physiochemical properties is a challenge. 
Cookson (Cookson, \& Beer, 2007) and Karlin (Karlin, \& Hogarth, 2005) on the other hand, described dithiocarbamate (dtc) as an extremely versatile ligand for metal ion-directed self-assembly. In dtc, the enhanced overlap of sulphur $\mathrm{p}$ orbital with metal $\mathrm{d}$ and $\mathrm{s}$ orbitals results in high binding energy with reduced charge transfer barrier across the metal-molecule interface (Wrochem et al., 2010). Therefore dithiocarbamate (dtc) ligands if utilised, could serve as a building block for molecular electronics. Zaroma et al. and others (Mitsumi et al., 2001) have utilized alkyl dithiocarbamate $\left(\mathrm{R}-\mathrm{CS}_{2}\right)$ ligand to synthesize conducting ICPs (Guijarro et al., 2010). Besides excellent conductivity, it lacks in optical properties simultaneously important for optoelectronic devices.

In this work, we report room temperature synthesis of $\mathrm{Co}$ (II) ICP nanowires (NWs) with dithiocarbamate ligand $\mathrm{Na}_{2}$ [dtc-SB-dtc] (SB = Bi-Schiff base Phenylene diamine). These Co(dtc-SB) NWs demonstrate tunable optical (absorption/emissions) properties and electronic conduction.

\section{Experimental}

\subsection{Materials and Physical Measurements}

Chemical reagents of AR grade were used for experimental work. Glyoxal (40\% aqueous), Methanol, dimethyl formamide, $p$-Phenylenediamine, carbon disulphide, sodium hydroxide and cobalt salt $\left(\mathrm{Co}(\mathrm{II}) \mathrm{Cl}_{2} \cdot 6 \mathrm{H}_{2} \mathrm{O}\right)$ were purchased from Merck. All solvents were distilled and kept with magnesium sulphate for several days to remove moisture. High Resolution Transmission electron microscopy (HRTEM) images, selected area electron diffraction patterns (SAED) and Energy-dispersive X-ray spectroscopy (EDX) results were obtained using transmission electron microscope (Philips Tecnai T-300). X-ray photoelectron spectrometer (XPS), Perkin-Elmer model 1257, was employed to study the chemical states, structure and composition of different elements present in the specimen. Fourier transform infrared (FTIR) spectra of ligand and complexes in $\mathrm{KBr}$ pellet were recorded using a Perkin-Elmer FT-IR spectrum BX spectrometer. Proton Nuclear Magnetic Resonance $\left({ }^{1} \mathrm{H}\right.$ NMR) spectroscopy was performed at $25{ }^{\circ} \mathrm{C}$ using a Jeol ECX-400P, $400 \mathrm{MHz}$ spectrometer in DMSO- $d_{6}$. The Electron paramagnetic resonance (EPR) spectra were recorded at RT and $77 \mathrm{~K}$ on a JES FA200 ESR Spectrometer at SAIF, IIT Bombay, India. UV-1601 Shimadzu UV-Vis spectrophotometer was used for recording the UV-Visible spectra of thin film of materials on glass substrate. Fluorescence measurement was conducted with a Cary Eclipse Spectrofluorimeter (Varian optical spectroscopy instruments, Mulgrave, Victoria, Australia). Elemental analysis was obtained from Elementer Analysensysteme GmbhVario E1-III instrument. TOF MS ES ${ }^{+}$spectra were recorded on MICROMASS (Waters) MODEL-KC 455. Thermogravimetric analysis (TGA) thermograms were recorded on RIGAKU, model 8150 Thermoanalyser (Thermaflex) in air flux. Conductivity measurement were carried out on metal complex pellet of known thickness and diameter (ca. 10 $\mathrm{mm}$ ) using two-point probe Keithley 2400, source meter. The powder sample was pressed at $200 \mathrm{~kg} \mathrm{~cm}^{-1}$ to form a pellet.

\subsection{Synthesis}

\subsubsection{Synthesis of Ligand dtc-SB}

Bis-dithiocarbamate Schiff base phenylenediamine ligand (dtc-SB) is synthesized with minor modification as reported (Gaur, Jain, Bhatia, Lal, \& Kaushik, 2013). Synthesis of dtc-SB is a two step process.

\subsection{1a. Synthesis of SB Ligand}

$p$-Phenylenediamine was used as a precursor to synthesize Bi-Schiff base phenylenediamine (SB). This SB ligand was used to synthesize tetradentate bis-dithiocarbamate Schiff base phenylenediamine ligand (dtc-SB). $100 \mathrm{ml}$ methanol $\left(\mathrm{CH}_{3} \mathrm{OH}\right)$ solution of $p$-Phenylenediamine $(60 \mathrm{mmol}, 6.48 \mathrm{~g})$ was stirred for 30 minutes in an ice bath. Then $100 \mathrm{ml}$ methanol solution of $\left(40 \mathrm{wt}\right.$ \% in $\left.\mathrm{H}_{2} \mathrm{O}\right)$ glyoxal $(30 \mathrm{mmol}, 1.74 \mathrm{~g})$ was added drop-wise to the homogenous solution and stirred for 75 minutes. Orange color precipitate formed. It was centrifuged and washed with $\mathrm{CH}_{3} \mathrm{OH}$ and kept for drying overnight in vacuum desiccator. Yield: $6.44 \mathrm{~g}$, (90\%). IR (solid state): $v(\mathrm{~N}-\mathrm{H}) \mathrm{cm}^{-1} 3412,3320,3218, v(\mathrm{C}=\mathrm{N}) \mathrm{cm}^{-1} 1607, v\left(\mathrm{C}-\mathrm{H}\right.$ out of-plane vibration) $\mathrm{cm}^{-1} 830 .{ }^{1} \mathrm{H}$ NMR (DMSO- $\left.d_{6}\right)$ : $\delta(\mathrm{ppm})=6.3\left[\mathrm{~s}, 4 \mathrm{H}, \mathrm{NH}_{2}\right], 6.59[\mathrm{~d}, 4 \mathrm{H}, \mathrm{ArH}], 7.2[\mathrm{~d}, 4 \mathrm{H}, \mathrm{ArH}], 8.35[\mathrm{~s}, 2 \mathrm{H}, \mathrm{H}-\mathrm{C}=\mathrm{N}]$. TOF MS ES $: \mathrm{m} / \mathrm{z}=238.52$ $\left[\mathrm{M}^{+}\right]$Anal: Calcd: $\mathrm{C}_{14} \mathrm{H}_{14} \mathrm{~N}_{4}$ : C,70.57; H,5.92; N,23.51. Found: C,70.54; H,5.93; N,23.53.

\subsection{1b. Synthesis of dtc-SB Ligand}

$1 \mathrm{mmol}$ of $\mathrm{SB}\left(238 \mathrm{mg}\right.$ ) and $2 \mathrm{mmol} \mathrm{NaOH}$ were dissolved in $100 \mathrm{ml}$ of $\mathrm{CH}_{3} \mathrm{OH}$ individually. These solutions were added dropwise in excessive $\mathrm{CS}_{2}$ with constant stirring at $20{ }^{\circ} \mathrm{C}$ simultaneously. The solution was stirred for $2 \mathrm{~h}$. Pale yellow precipitate was formed, which was centrifuged and washed with $\mathrm{CH}_{3} \mathrm{OH}$ and kept for drying overnight in vacuum desiccator. Yield: $0.316 \mathrm{~g},(72.6 \%)$. IR (solid state): $\mathrm{v}(\mathrm{N}-\mathrm{H}) \mathrm{cm}^{-1} 3385,646, \mathrm{v}(\mathrm{H}-\mathrm{C}=\mathrm{N}) \mathrm{cm}^{-1}$ 2929, $v(\mathrm{C}-\mathrm{H}) \mathrm{cm}^{-1} 2364, v(\mathrm{C}=\mathrm{N}) \mathrm{cm}^{-1} 1605, v(\mathrm{C}=\mathrm{C}) \mathrm{cm}^{-1}$ 1507, $v(\mathrm{C}-\mathrm{N}) \mathrm{cm}^{-1} 1216, \quad \mathrm{C}(\mathrm{C}=\mathrm{N}) \mathrm{cm}^{-1} 1390$, 
$v(\mathrm{~S}=\mathrm{C}-\mathrm{S}) \mathrm{cm}^{-1} 1052,1004, v(\mathrm{C}-\mathrm{H}$ out of-plane vibration $) \mathrm{cm}^{-1} 826 .{ }^{1} \mathrm{H}$ NMR $\left(\mathrm{DMSO}-d_{6}\right): \delta(\mathrm{ppm})=5.5[\mathrm{~s}, 2 \mathrm{H}$, $-\mathrm{NH}$ ], $6.59[\mathrm{~d}, 4 \mathrm{H}, \mathrm{ArH}], 7.2[\mathrm{~d}, \quad 4 \mathrm{H}, \mathrm{ArH}], 8.35[\mathrm{~s}, 2 \mathrm{H}, \mathrm{H}-\mathrm{C}=\mathrm{N}]$. TOF MS ES ${ }^{+}: \mathrm{m} / \mathrm{z}=436.01\left[\mathrm{M}^{+}+2 \mathrm{H}\right]$ Anal: Calcd: $\mathrm{C}_{16} \mathrm{H}_{12} \mathrm{~N}_{4} \mathrm{Na}_{2} \mathrm{~S}_{4}$ : C,44.22; H,2.78; N,12.89. Found: C,44.24 H,2.75; N,12.84.

\subsubsection{Synthesis of $\left[\mathrm{Co}(\mathrm{dtc}-\mathrm{SB}) \cdot 2 \mathrm{H}_{2} \mathrm{O}\right]_{\mathrm{n}},(\mathrm{Co}(\mathrm{dtc}-\mathrm{SB}))$ Infinite Coordinated Polymer Nanowires}

Bis-dithiocarbamate Schiff base phenylenediamine ligand (dtc-SB) $(1 \mathrm{mmol}, 436 \mathrm{mg})$ was dissolved in dimethyl formamide solution. To this solution, add cobalt(II) chloride hexahydrate $(1 \mathrm{mmol}, 237 \mathrm{mg})$. It was stirred for 3 to $4 \mathrm{~h}$ in dark. Brown colour precipitate formed after slow addition of pentene. It was centrifuged and washed with $\mathrm{CH}_{3} \mathrm{OH}$ :DMF (9:1) mixture and was kept for drying over $\mathrm{P}_{2} \mathrm{O}_{5}$ in vacuum desiccator overnight. Yield: 402 $\mathrm{mg},(76.30 \%)$. IR (solid state): $v(\mathrm{~N}-\mathrm{H}) \mathrm{cm}^{-1} 3310$ (H-bonded), 634, $v(\mathrm{H}-\mathrm{C}=\mathrm{N}) \mathrm{cm}^{-1} \quad 2962, \mathrm{v}(\mathrm{C}-\mathrm{H}) \mathrm{cm}^{-1} 2360$, $v(\mathrm{C}=\mathrm{N}) \mathrm{cm}^{-1} 1600($ H-bonded $), v(\mathrm{C}=\mathrm{C}) \mathrm{cm}^{-1} 1512, v(\mathrm{C}-\mathrm{N}) \mathrm{cm}^{-1} 1232, v(\mathrm{C}=-\mathrm{N}) \mathrm{cm}^{-1} 1410, \quad v(\mathrm{~S}=\mathrm{C}-\mathrm{S}) \mathrm{cm}^{-1}$ 1062, v(C-H out of-plane vibration) $\mathrm{cm}^{-1}$ 826. TOF MS ES $: \mathrm{m} / \mathrm{z}=483$ Anal: Calcd: $\mathrm{C}_{16} \mathrm{H}_{16} \mathrm{~N}_{4} \mathrm{O}_{2} \mathrm{~S}_{4} \mathrm{Co}$ : C,39.74; H,3.34; N,11.59. Found: C, 39.62; H,3.29; N,11.67.

\section{Results and Discussion}

\subsection{Synthesis}

Synthesis of dtc-SB ligand and its cobalt complex (Co(dtc-SB)) is presented in Scheme 1. Schiff base Phenylenediamine ligand (SB) was first prepared using $p$-Phenylenediamine which get condensed with glyoxal to form imine bridged ligand SB. Direct introduction of aromatic rings in the ligand decreases the flexibility for structural change and consequently deactivate reactivity (Tabata, Tokoyama, Yamakado, \& Okuno, 2012). In order to avoid any strain in the ligand conjugated system, aromatic rings are bridged using diimine to maintain the planarity. The SB ligand further reacts with $\mathrm{CS}_{2}$ in presence of $\mathrm{NaOH}$ to form dtc-SB. So obtained pale yellow product was washed with $\mathrm{CH}_{3} \mathrm{OH} / \mathrm{DMF}(9: 1: \mathrm{v} / \mathrm{v})$ thrice and purity of the ligand was estimated using TLC and ${ }^{1} \mathrm{H}$ NMR spectroscopy. In all attempts, TLC analysis of the product shows single spot and its corresponding ${ }^{1} \mathrm{H}$ NMR spectrum (S1, ESI) indicates peaks corresponding to 4 different protons. Purified dtc-SB was further allowed to react with $\mathrm{CoCl}_{2} \cdot 6 \mathrm{H}_{2} \mathrm{O}$ (1:1 molar) in $\mathrm{DMF}$, followed by gradual pentane vapour diffusion to form $\mathrm{Co}(\mathrm{dtc}-\mathrm{SB})$. Due to the diffusion of low polarity pentane, solubility of the complex decreased and aggregates were formed. HRTEM image (Fig. 1) shows that the Co(dtc-SB) forms well defined nanowires (NWs) (30 nm dia.). Selected area electron diffraction (SAED) pattern (inset Fig. 1b) in agreement with X-ray diffraction (not shown) results reveal the amorphous nature. 1D growth tendency is retained due to introduction of diimine maintaining high degree of planarity in the ligand. Consequently, it results in effective $\pi-\pi$ interaction to form NWs.

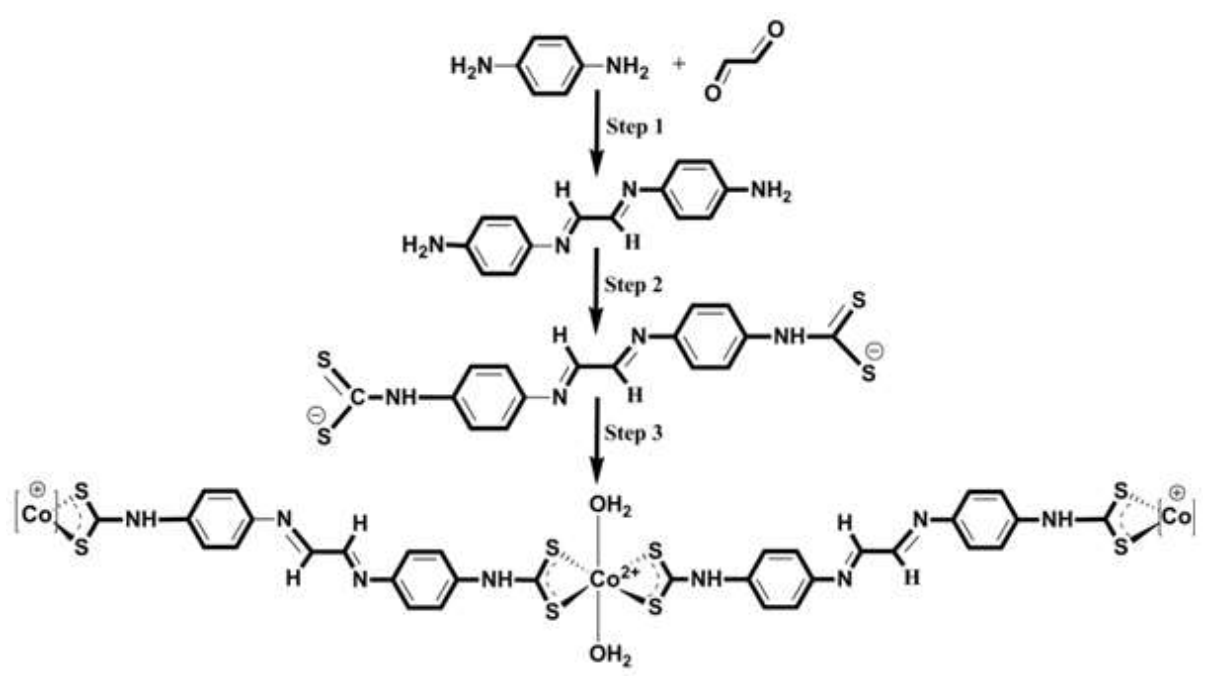

Scheme 1. Synthesis route of dtc-SB and Co(dtc-SB) Step 1: $\mathrm{CH}_{3} \mathrm{OH}, 0-5^{\circ} \mathrm{C}$; Step 2: $\mathrm{CH}_{3} \mathrm{OH}, \mathrm{NaOH}$, $\mathrm{CS}_{2}$ (excess), $20{ }^{\circ} \mathrm{C} ; \quad$ Step 3: DMF, $\mathrm{CoCl}_{2} \cdot 6 \mathrm{H}_{2} \mathrm{O}$, RT. 

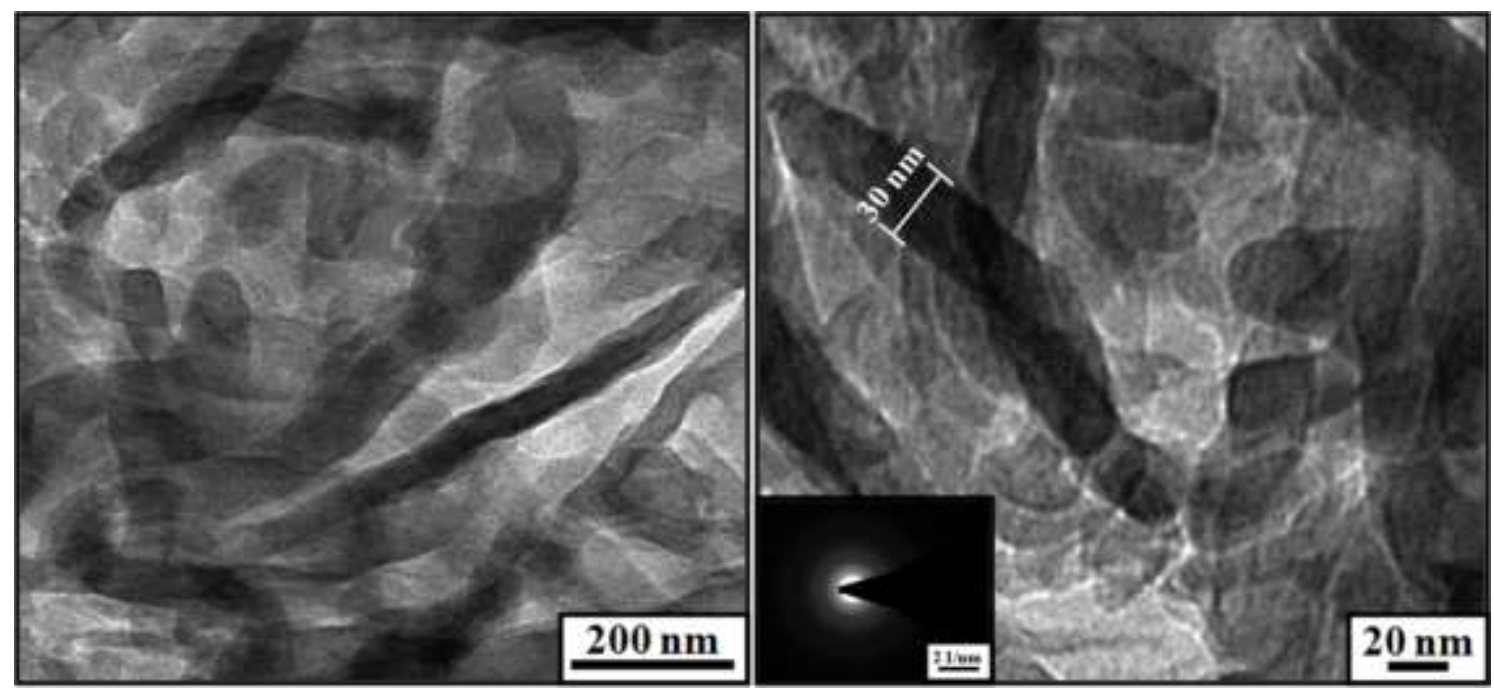

Figure 1. TEM images of (a) Co(dtc-SB) nanowires. (b) High resolution image, SAED (inset) show diffused rings pattern as a characteristics of amorphous nature.

\subsection{Characterization}

$\mathrm{Co}(\mathrm{dtc}-\mathrm{SB})$ motif is particularly interesting, as $\mathrm{Co}(\mathrm{II})$ dithiocarbamate complexes are comparatively rare due to their high susceptibility towards oxidation (Karlin et al., 2005). Fabretti et al. and Harding et al. studied the role of substituent on electron donation ability of $\mathrm{C}=\mathrm{N}$ and $\mathrm{C}=\mathrm{-}-\mathrm{S}$ bonds of dithiocarbamate ligands. They inferred that the benzyl substituted dithiocarbamate ligand could stabilize cobalt (II) complexes (Fabretti, Forghieri, Giusti, Preti, \& Tosi, 1984; Harding, Harding, Dokmaisrijan, \& Adams, 2011). This suggests that the synthesized dtc-SB ligand is vital to the successful synthesis of air stable $\mathrm{Co}(\mathrm{II})$ dithiocarbamate compounds. The Co(dtc-SB) NWs is highly resistive, so it is doped to generate mobile charges in $\pi$-electronic structure. These mobile charges are compensated by counter-ions which diffuse between the conjugated chains and $\mathrm{Co}(\mathrm{dtc}-\mathrm{SB})$ exist as salts (Heeger, 2001). Iodine $\left(\mathrm{I}_{2}\right)$ and Sodium naphthalide in different concentrations are used as $\mathrm{p}$ and n-type dopant respectively (S2, ESI). When Co(dtc-SB) is exposed to iodine vapour, doping occurs through following chemical reaction.

$$
3 / 2 \mathrm{xy}\left(\mathrm{I}_{2}\right)+[\mathrm{Co}(\mathrm{dtc}-\mathrm{SB})]_{\mathrm{x}} \rightarrow\left[[\mathrm{Co}(\mathrm{dtc}-\mathrm{SB})]^{+\mathrm{y}}\left(\mathrm{I}_{3}{ }^{-}\right)_{\mathrm{y}}\right]_{\mathrm{x}}
$$

Here $\mathrm{I}_{2}$ serves as oxidising agent and $\mathrm{I}_{3}{ }^{-}$as counter-ion.

During n-type doping, naphthalene- serves as the reducing agent and $\mathrm{Na}^{+}$is the counter ion.

$$
\mathrm{y}\left(\mathrm{Na}^{+}\right)\left(\text {naphtha }{ }^{-}\right)+[\mathrm{Co}(\mathrm{dtc}-\mathrm{SB})]_{\mathrm{x}} \rightarrow\left[\mathrm{Na}^{\mathrm{y}+}\left[\mathrm{Co}(\mathrm{dtc}-\mathrm{SB})^{-\mathrm{y}}\right]_{\mathrm{x}}+(\text { naphtha })_{\text {neutral }}\right.
$$

Elemental analysis of Co(dtc-SB) with and without doping is presented in Table S1, ESI. Iodine doping in $\mathrm{Co}(\mathrm{dtc}-\mathrm{SB})$ is studied at low concentration i.e. $9.8 \mathrm{wt} \% \mathrm{I}_{2}$ and high as $20.2 \mathrm{wt} \%$. Similarly, Sodium doping in $\mathrm{Co}(\mathrm{dtc}-\mathrm{SB})$ is studied at $5.4 \mathrm{wt} \%$ and $11.53 \mathrm{wt} \%$. Upon $\mathrm{p}$ and/or $\mathrm{n}$ doping, polymer structure remains intact and the partial oxidation involves orbitals which are largely of ligand in percentage (Diel et al., 1984).

Fig. 2 shows XPS spectra of the Co 2p, C 1s, N 1s, S 2p and O 1s. The spectrum of Co 2p exhibits complex satellite structure as shown in Fig. 2a. Binding energy difference $(\Delta \mathrm{E} 15 \mathrm{eV})$ between Co $2 \mathrm{p}_{1 / 2}$ and Co $2 \mathrm{p}_{3 / 2}$ with pair of satellites support that Co(dtc-SB) is a hexa coordinated cobalt(II) complex (Atzei, Rossi, \& Sadun, 2000; Baba, \& Nakano, 2012; Battistoni, Gastaldi, Mattogno, Simeone, \& Viticoli, 1987). Different peaks in C1s spectrum (Fig. 2b) are attributed to the chemically inequivalent carbons. The intensity of peaks depend on the tautomeric conformation adopted by the molecule. Peak at $287.6 \mathrm{eV}$ is assigned to electron deficient carbon connected to the electronegative nitrogen atom $(\mathrm{C}=\mathrm{N})$ whereas, $286.2 \mathrm{eV}$ peak shows two components C-N/C-S (Wohlgemuth, White, Willinger, Titirici, \& Antonietti, 2012). The area under C-N/C-S peak is thrice of $\mathrm{C}=\mathrm{N}$ peak, which is in agreement to the proposed molecular structure. The main carbon peak at $284.6 \mathrm{eV}$ is assigned to benzene like carbon atoms ( $\mathrm{sp}^{2} \mathrm{C}-\mathrm{C}$ or C-H) (Wohlgemuth et al., 2012). XPS spectrum of N 1s (Fig. 

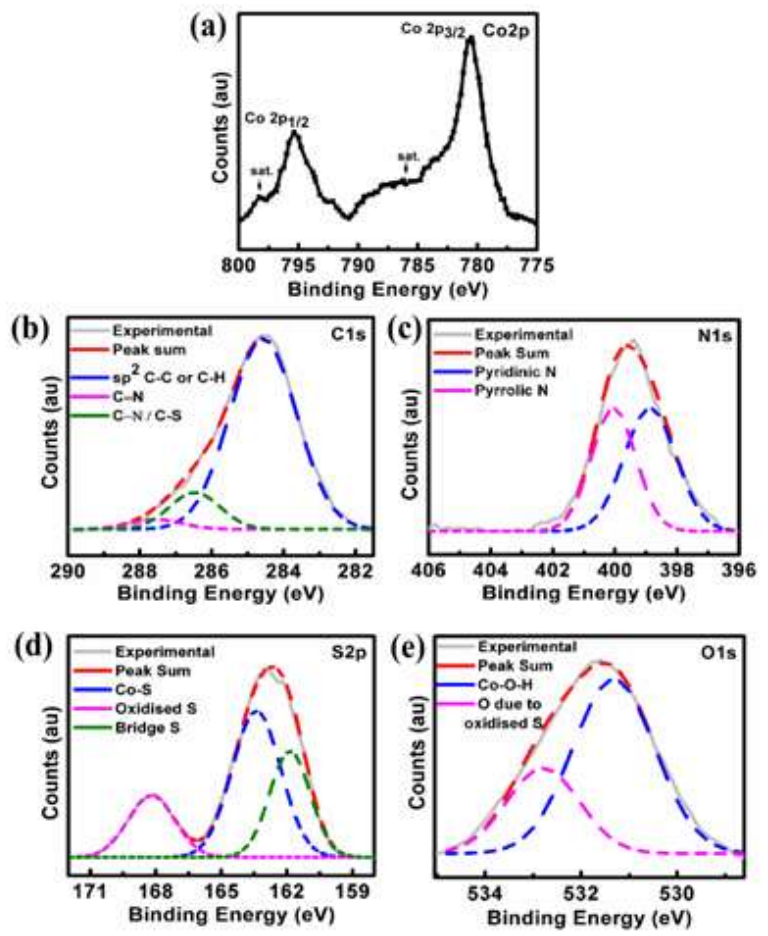

Figure 2. XPS Spectra of (a) hexa coordinated Co 2p. (b) C 1s. (c) N 1s. (d) S 2p and (e) O 1s.

Table 1. Binding Energy of different peaks in XPS spectra.

\begin{tabular}{ccc}
\hline Peak & $\begin{array}{c}\text { Binding } \\
\text { energy }(\mathbf{e V})\end{array}$ & Assignment \\
\hline Co 2p & 780.4 & $2 \mathrm{p}_{3 / 2}$ \\
& 795.3 & $2 \mathrm{p}_{1 / 2}$ \\
$\mathrm{C}$ 1s & 284.6 & $\mathrm{Sp}^{2} \mathrm{C}-\mathrm{C}$ or C-H \\
& 286.2 & $\mathrm{C}-\mathrm{N} / \mathrm{C}-\mathrm{S}$ \\
& 287.6 & $\mathrm{C}=\mathrm{N}$ \\
$\mathrm{N}$ 1s & 398.7 & N1 pyridinic \\
& 400.1 & N2 pyrrolic \\
S 2p & 161.8 & Co-S-R \\
& 162.9 & Bridge S \\
& 168.1 & Oxidised S \\
O 1s & 531.1 & Co-O-H \\
& 532.5 & Due to oxidised S \\
\hline
\end{tabular}

2c) shows two peaks at 400.1 and $398.7 \mathrm{eV}$ corresponding to the pyrrolic nitrogen and pyridinic nitrogen (Wohlgemuth et al., 2012) with an area ratio 1:1. Peaks in S 2p spectrum (Fig. 2d) at $161.8 \mathrm{eV}$ and $162.9 \mathrm{eV}$ confirm the presence of cobalt bound sulphur (Co-S-R) and bridged sulphur (Atzei et al., 2000; Baba et al. 2012) respectively which is in close agreement with the molecular structure proposed by N. Giroud et al. for $\mathrm{Zn}$ and Mn dithiocarbamate complexes (Giroud, Dorge, \& Trouve, 2010). Peak at $168.1 \mathrm{eV}$ in S 2p spectrum originates from oxidised sulphur is correlated with the peak at $532.5 \mathrm{eV}$ of $\mathrm{O} 1 \mathrm{~s}$ spectra in Fig. 2e. This oxidised sulphur peak could be due to the absorbed oxygen in Co(dtc-SB) NWs (Yang, Sun, Guo, \& Da, 1999). Peak at 531.1eV in $\mathrm{O}$ 1s indicates the presence of Co-O-H in the structure (Atzei et al., 2000; Baba et al. 2012). Different peaks assigned in the spectra along with their binding energies are shown in Table 1. This confirms that the above results are in correlation with proposed $\mathrm{Co}(\mathrm{dtc}-\mathrm{SB})$ structure, where each $\mathrm{Co}(\mathrm{II})$ hexa coordinated metal centre possess two dithiocarbamate ligand in bidentate mode and two $\mathrm{H}_{2} \mathrm{O}$ molecule in axial positions. Further investigation on different functionalities present in the ligand structure and the change in electronic states upon complexation and doping are analyzed using FTIR. Stretching vibrations at $1052 \mathrm{~cm}^{-1}\left(\mathrm{CS}_{\text {2asymmetric stretching }}\right)$, $1004 \mathrm{~cm}^{-1}\left(\mathrm{CS}_{2 \text { symmetric stretching }}\right), 1390 \mathrm{~cm}^{-1}(\mathrm{C}-\mathrm{N}$ stretching $)$ and $1605 \mathrm{~cm}^{-1}(\mathrm{C}=\mathrm{N}$ stretching $)$ of the dtc-SB in FTIR spectrum (Fig. 3a) confirms the presence of the dithiocarbamate and imine moieties (Gaur et al., 2013). 
Peaks at $3385 \mathrm{~cm}^{-1}$ and $646 \mathrm{~cm}^{-1}$ correspond to anti-symmetric and rocking stretching vibration of N-H (Pavia, Lampman, Kriz, \& Vyvyan, 2007; Kross, Fassel, \& Margoshes, 1956) (Fig. S3, ESI). FTIR results show that the characteristic absorption of dtc-SB at $1004 \mathrm{~cm}^{-1}\left(\mathrm{CS}_{2 \text { symmetric stretching }}\right)$ disappeared after the complex formation with cobalt (Fig. 3b). Major (ca. $10 \& 20 \mathrm{~cm}^{-1}$ ) shift in wave number of the characteristic absorption peak for anti-symmetric stretching vibration of $\mathrm{CS}_{2}$ at $1052 \mathrm{~cm}^{-1}$ and $\mathrm{S}_{2} \mathrm{C}-\mathrm{\cdots}-\mathrm{N}$ stretching vibration at $1390 \mathrm{~cm}^{-1}$ support the complexation of Cobalt with dithiocarbamate moiety resulting in linear chain structure. Change in electronic structure of $\mathrm{I}_{2}$ doped and Na doped $\mathrm{Co}(\mathrm{dtc}-\mathrm{SB})$ (Fig. $3 \mathrm{c} \& \mathrm{~d}$ ) is attributed to formation of charge transfer complex between dopant and the conjugated system (Dai, 1992). Broad peaks at 1605 and $1486 \mathrm{~cm}^{-1}$ in the IR spectrum of $\mathrm{I}_{2}$ doped $\mathrm{Co}(\mathrm{dtc}-\mathrm{SB})$ and peaks at 1597 and $1458 \mathrm{~cm}^{-1}$ for Na doped Co(dtc-SB) are characteristic of nitrogen quinoid and benzenoid structure. Their presence strongly support the conducting state of conjugated system (Collman et al., 1986 \& Dhawan, \& Trivedi, 1992). The broadening of electronic absorptions on going from undoped to the doped $\mathrm{Co}(\mathrm{dtc}-\mathrm{SB})$ is credited to the low electronic transitions. This is often found as a signature of highly conductive materials and are thought to result from either inter or intra valence band transition (Dhawan et al., 1992). Moreover, the desired formation of ligand and its complex Co(dtc-SB) is also confirmed by ${ }^{1} \mathrm{H}-\mathrm{NMR}$ and X-band EPR respectively. The ${ }^{1} \mathrm{H}$ NMR of dtc-SB shows resonance signals corresponding to 4 different protons in different electronic environment. The broad peak for $\mathrm{N}-\mathrm{H}$ protons appears at $\delta 5.5 \mathrm{ppm}$ whereas aromatic protons appear at $\delta 6.5 \mathrm{ppm}$ and $\delta 7.2 \mathrm{ppm}$ respectively (Kross et al., 1956; West, Stark, Bain, \& Leberta, 1996). The higher denomination of $\delta 8.3 \mathrm{ppm}$ is assigned to imine protons (S1, ESI) (Gaur et al., 2013). First-derivative X-band EPR spectra of powdered Co(dtc-SB) NWs is recorded at room temperature (RT) and liquid $\mathrm{N}_{2}(77 \mathrm{~K})$ to analyse the coordination geometry around the Co ion. The $\mathrm{X}$-band spectra are not well-resolved at RT, however an orthorhombic spectrum with hyperfine splitting pattern of high-spin $\mathrm{Co}^{2+}$ in octahedral sites is observed at $77 \mathrm{~K}$ (Fiorani, Gastaldi, \& Viticoli, 1983) (Fig. 4). Furthermore, very short spin-lattice relaxation time and strong anisotropy of the $\mathrm{g}$ factor percluding hyperfine splitting of EPR

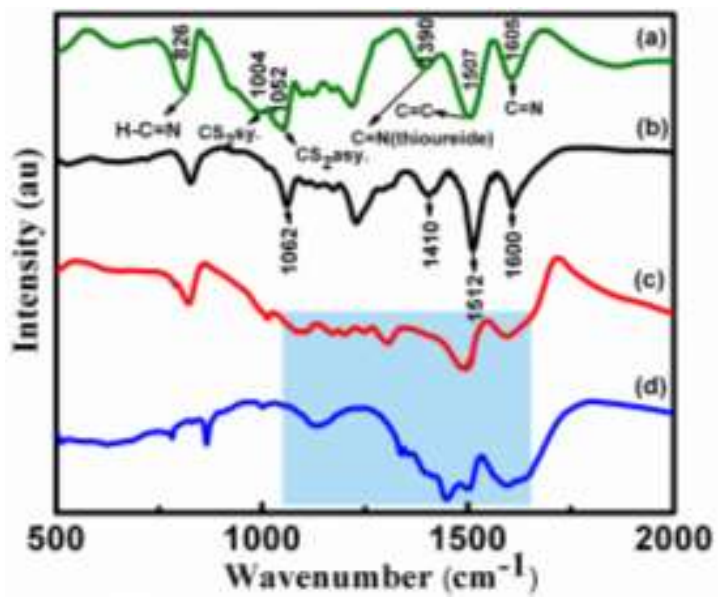

Figure 3. FTIR spectra of (a) ligand dtc-SB. (b) Cobalt complex Co(dtc-SB). (c) $I_{2}$ (p) doped Co(dtc-SB) and (d) $\mathrm{Na}(\mathrm{n})$ doped $\mathrm{Co}(\mathrm{dtc}-\mathrm{SB})$. The peaks of IR spectrum are described in the order they appeared in the structures (See Scheme 1).

signal are characteristics of $\mathrm{Co}$ (II) ions in octahedral sites . At LNT, the observed spectra for Co(dtc-SB) complex can be described in terms of a spin doublet $S^{\prime}=1 / 2$ that arises from the splitting of the octahedral ground state ${ }^{4} \mathrm{~T}_{1}$ for $\mathrm{Co}^{2+}$ ions by the low-symmetry field and spin-orbit coupling (Fiorani et al., 1983; Nunez et al., 2011). The calculated EPR parameters, $g_{I I}=2.168 \& g_{\perp}=2.077$ are consistant with those found for $\mathrm{Co}^{2+}$ ions in octahedral geometry [44]. In addition, the TOF MS ES ${ }^{+}$indicates the presence of the bridging ligand dtc-SB at $\mathrm{m} / \mathrm{z} 388.6$ which supports the imine bridged dithiocarbamate ligand remains intact in the polymer backbone. Chemical composition of Co(dtc-SB) NWs using Elemental analysis and energy dispersed X-ray (EDX) spectroscopy (S4, ESI) further support the presence of cobalt, carbon, nitrogen and sulphur in 1:1 cobaltligand complex. Further quantification was done by thermal analysis. dtc-SB differs significantly in thermal properties from its cobalt complex. Most striking difference is the char residue which in case of Co(dtc-SB) is about $15 \%$ whereas negligible char residue is obtained from dtc-SB. The char residue of Na doped Co(dtc-SB) is $\sim 22 \%$, while in case of $\mathrm{I}_{2}$ doping this reduces to $17 \%$ (Fig. 5). TG thermogram of dtc-SB shows three decomposition steps. The first decomposition due to dehydration occurs between $50-200{ }^{\circ} \mathrm{C}$ with $\sim 10 \%$ mass loss. Subsequent mass loss $(\sim 35 \%)$ between 200 and $480{ }^{\circ} \mathrm{C}$ is attributed to the breakdown of dithiocarbamate 
moiety (Raja, Bhuvanesh, \& Natarajan, 2012). The third and final mass loss between $490{ }^{\circ} \mathrm{C}$ to $780{ }^{\circ} \mathrm{C}$ occurs due to decomposition of the organic part of the ligand (Giovagnini et al., 2008). $\mathrm{Co}$ (dtc-SB) also follows the similar three stage degradation trend as observed for dtc-SB however shows better stability. Two molecules of $\mathrm{H}_{2} \mathrm{O}$ as calculated from the percentage mass loss has been dehydrated at $200{ }^{\circ} \mathrm{C}$. The char residue may be Co oxide. The TGA curves of Co(dtc-SB) confirm that the thermal stability of dtc-SB is enhanced on complexation with Co. $\mathrm{I}_{2}$ doped $\mathrm{Co}\left(\mathrm{dtc}-\mathrm{SB}\right.$ ) decomposes sharply at about $135^{\circ} \mathrm{C}$ due to the elimination of free $\mathrm{I}_{2}$ (Giovagnini et al., 2008). However, there is no considerable change in the TG behaviour after $\mathrm{Na}$ doping in $\mathrm{Co}(\mathrm{dtc}-\mathrm{SB})$.

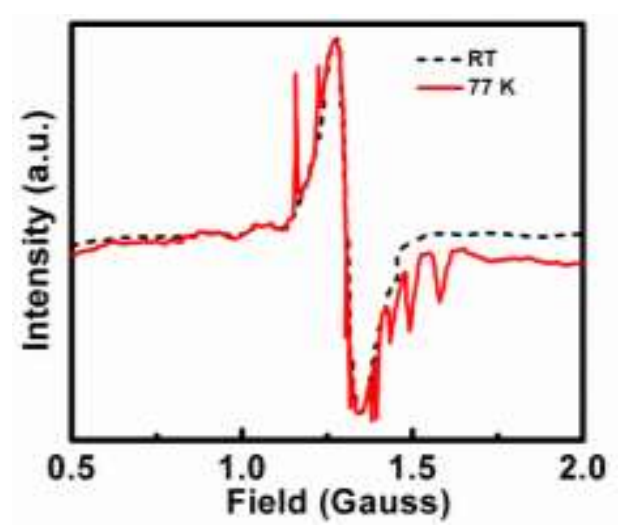

Figure 4. EPR spectra of Cobalt complex $\mathrm{Co}(\mathrm{dtc}-\mathrm{SB})$ at room temperature and liquid $\mathrm{N}_{2}(77 \mathrm{~K})$.

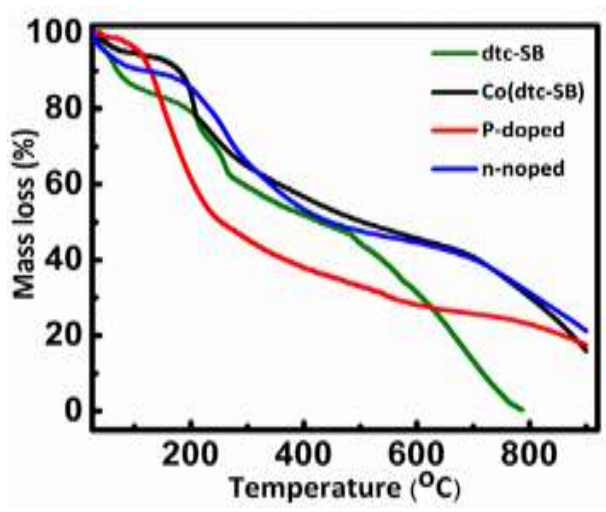

Figure 5. TGA thermograms of synthesized ligand dtc-SB; its cobalt complex $\mathrm{Co}(\mathrm{dtc}-\mathrm{SB}) ; \mathrm{I}_{2}$ (p) doped $\mathrm{Co}(\mathrm{dtc}-\mathrm{SB})$ and $\mathrm{Na}(\mathrm{n})$ doped $\mathrm{Co}(\mathrm{dtc}-\mathrm{SB})$.

\subsection{Optical Properties of Co(dtc-SB) NWs}

$\mathrm{Co}(\mathrm{dtc}-\mathrm{SB})$ is a brown powder with yellowish tinge in solution. In order to examine the optical properties of Co(dtc-SB) NWs, optical absorption of thin film and optical emission spectra in DMSO solution was recorded (Fig. 6). The extent of conjugation in a conjugated system directly affects the observed energy of $\pi-\pi^{*}$ transitions i.e. the maximum absorption $\left(\lambda_{\max }\right)$. Quantitative comparison of thin film UV-Vis spectra of neutral and doped Co(dtc-SB) show change in absorption due to different $\pi-\pi^{*}$ transitions. These transitions occur between the charge transfer complex formed between dopant and conjugated system. Absorption edge of doped and undoped Co(dtc-SB) extends about $590-685 \mathrm{~nm}$, from which the optical band gap energy difference $\left(\mathrm{E}_{\mathrm{g}}\right)$ is calculated using the Tauc equation: $(\alpha \mathrm{h} v)^{\mathrm{n}}=\mathrm{K}\left(\mathrm{h} v-\mathrm{E}_{\mathrm{g}}\right)$. The plot of $(\alpha \mathrm{h} v)^{2} v \mathrm{~s} . \mathrm{h} v$ is plotted and $\mathrm{E}_{\mathrm{g}}$ is determined from the extrapolated intercept on the energy ( $\mathrm{h} v$ ) axis (Inset Fig. 6 a). The $\mathrm{E}_{\mathrm{g}}$ of the Co(dtc-SB) is estimated to be 2.1 $\mathrm{eV}$ and for that of $\mathrm{Na}$ and $\mathrm{I}_{2}$ doped $\mathrm{Co}(\mathrm{dtc}-\mathrm{SB})$ is $2.04 \mathrm{eV}$ and $1.8 \mathrm{eV}$ respectively. Fig. $6 \mathrm{~b}$ shows the photograph of the Co(dtc-SB) (undoped \& doped) DMSO solution $(1 \mathrm{mg} / \mathrm{ml}$ ), which was utilized to study its emission spectroscopy, as discussed in the next section.

Fluorescence emission spectra of the Co(dtc-SB) NWs with and without doping in DMSO solution $(1 \mu \mathrm{g} / \mathrm{ml}) \mathrm{was}$ investigated. dtc-SB does not show any noticeable fluorescence upon excitation at $380 \mathrm{~nm}$ whereas Co(dtc-SB) and its doped derivatives display very strong fluorescence extended to about 455-526 nm with stokes shift of $\sim 75$ $\mathrm{nm}$ to $146 \mathrm{~nm}$, shown in Fig. 6c. This implies that emission behaviour arises as a result of ligand-metal charge 
transfer (LMCT). The $\mathrm{I}_{2}$ doped Co(dtc-SB) displays fluorescence emission with stokes shift of $146 \mathrm{~nm}$ whereas the Na doped sample exhibits $86 \mathrm{~nm}$ stokes shift. High fluorescent behaviour in $\mathrm{Co}(\mathrm{dtc}-\mathrm{SB}) \mathrm{NWs}$ is attributed to the complex formation leading to reduction of PET process (Sreedaran et al., 2008). Four membered chelate ring present in $\mathrm{Co}(\mathrm{dtc}-\mathrm{SB})$ increases rigidity in comparison to free ligand, which in turn, reduces the loss of energy by vibrational decay and enhances the fluorescence intensity (Pandey et al., 2011). The efficient quenching of the emission intensity on $\mathrm{I}_{2}$ and $\mathrm{Na}$ doping suggests the effective energy transfer from dopant ions to NWs, which is also seen in FTIR results (Peng, Xiao, Ma, Yang, \& Yao, 2005). Efficient energy transfer is reflected in multifold increase in conductivity of doped samples. Fluorescence emission behaviour of the Co(dtc-SB) NWs is comparable to that of other fluorescent supramolecular polymeric nanowires (Luo et al., 2009). Remarkably, the high fluorescence behaviour of complexes is confirmed in acetonitrile and found that it produced measurable signal even in nanomolar $(\mathrm{nm})$ range.

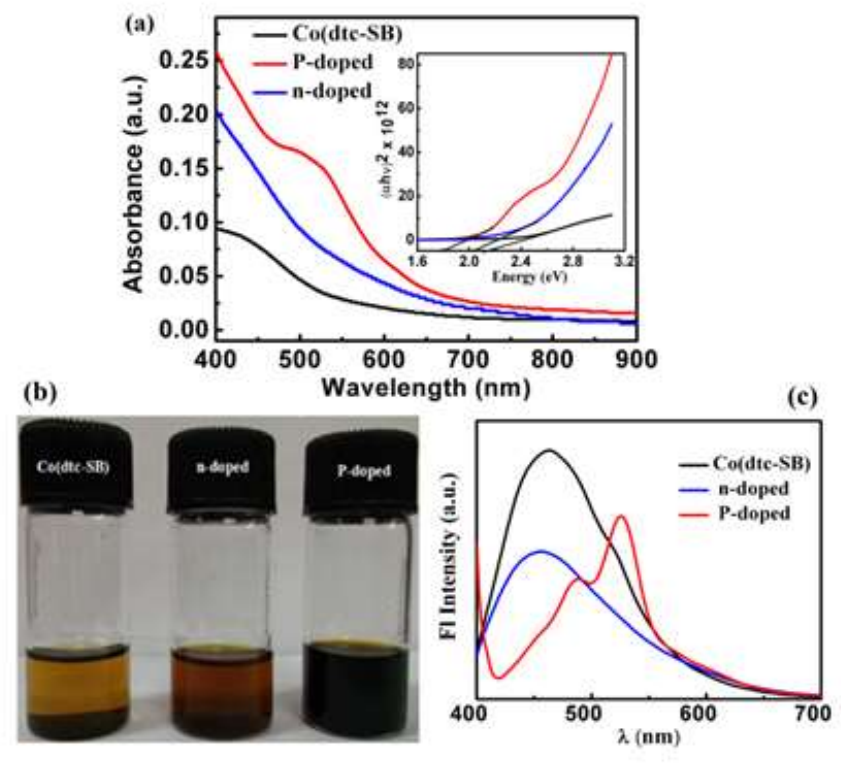

Figure 6. (a) Uv-vis absorption spectrum of Co(dtc-SB), $\mathrm{I}_{2}$ doped Co(dtc-SB)and Na doped Co(dtc-SB) thin film : Inset graph shows a plot of $\mathrm{h} v$ versus $(a \mathrm{~h} v)^{2}$ of Co(dtc-SB)and its doped derivatives. (b) Estimated optical band gap commensurate with the color of samples in DMSO solution. (c) Fluorescence spectra of Co(dtc-SB) and its doped derivatives. $\lambda_{\mathrm{ex}}=380 \mathrm{~nm}, \lambda_{\mathrm{em}}=455-526 \mathrm{~nm}$, slit width $(5 \mathrm{~nm} / 5 \mathrm{~nm}, 500 \mathrm{~V}$ PMT).

\subsection{Conductivity Study}

Fig. 7a shows the current-voltage (I-V) characteristics of low concentration (9.8\%) $\mathrm{I}_{2}$ doped Co(dtc-SB) NWs between $300-425 \mathrm{~K}$. I-V curves are linear in -5 to $5 \mathrm{~V}$ voltage range confirming ohmic behaviour. Current in the $\mathrm{I}_{2}$ doped $\mathrm{Co}(\mathrm{dtc}-\mathrm{SB}) \mathrm{NWs}$ is increased by two order of magnitude, when temperature is raised from $300 \mathrm{~K}$ to 425 $\mathrm{K}$. Resistance (R) calculated from the slope of the curve is $\sim 28 \mathrm{Mohm}$ at $300 \mathrm{~K}$, which gradually decreases to $300 \mathrm{kohm}$ on increasing temperature $(425 \mathrm{~K})$. I-V plots of the high $(20.2 \%) \mathrm{I}_{2}$ doped Co(dtc-SB) NWs in $300-400 \mathrm{~K}$ temperature range (Fig. $7 \mathrm{~b}$ ) show linear trend only in the range of -1 to $1 \mathrm{~V}$. Above this range I-V characteristics deviates from the linear trend but they remain symmetric. The resistance $(\mathrm{R})$ of the high $\mathrm{I}_{2}$ doped $\mathrm{Co}(\mathrm{dtc}-\mathrm{SB}) \mathrm{NWs}$ is found to be $60 \mathrm{kohm}$ at $300 \mathrm{~K}$ which decreases to $7 \mathrm{kohm}$ at $400 \mathrm{~K}$. The high $\mathrm{I}_{2}$ doped sample is more conducting (by 3 orders of magnitude) compared to low doped sample. TG analysis shows that material degrades above this temperature and this fact is also reflected in I-V curve which exhibits increase in $R$ above $400 \mathrm{~K}$. Non-linearity in high doped $\mathrm{I}_{2} \mathrm{Co}(\mathrm{dtc}-\mathrm{SB}) \mathrm{NWs}$ may be due to scattering between the Co and $\mathrm{I}_{2}$ or $\mathrm{I}_{2}-\mathrm{I}_{2}$ atoms. High doping concentration of $\mathrm{I}_{2}$ induces additional disorder and hopping centres and the effect becomes prominent (Zakirov et al., 2011).

To study n-type conduction, Co(dtc-SB) NWs were doped with Na-naphthalide. I-V curve for low (5.4\%) Na doped Co(dtc-SB) NWs shows an entirely different behaviour from $\mathrm{p}$ type doping (Fig. 7c). I-V characteristics are asymmetric and show rectification in positive voltage regime. At +ve low voltage $(<1$ volts $)$ the I-V curve is linear and the $\mathrm{R}$ of the sample is found to be $\sim 3 \mathrm{Mohm}$. Upon increasing the Na doping level to $11.5 \%$, I-V curve becomes more symmetric as shown in Fig. 7 d. We also noticed that current does not falls to $\sim 0$ at 0 voltage because of hysteresis observed in polymeric material (Hwang, Oh, Hwang, Kim, \& Im, 2008). 
Fig. 8 shows the R vs $1 / \mathrm{T}$ plot for doped complexes in semi logarithmic scale. Inset of Fig. $8 \mathrm{a}$ is $\mathrm{R}$ vs $\mathrm{T}$ plot for low $\mathrm{I}_{2}$ doped $\mathrm{Co}(\mathrm{dtc}-\mathrm{SB}) \mathrm{NWs}$. The $\mathrm{R}$ of the sample is $28 \mathrm{Mohm}$ which decreases to $300 \mathrm{kohm}$ with increase in temperature to $425 \mathrm{~K}$ indicate semiconducting behaviour. Consequently, conductivity increased from $2.2 \mathrm{E}-8$ to 1.4E-5 Scm$~^{-1}$. In order to ascertain the conduction mechanism, $\log \mathrm{R}$ vs $1 / \mathrm{T}$ plotted in Fig. 8a show two different slopes. This kind of behaviour is reported earlier in doped polymeric sample (Tabata et al, 2012). This plot is linear with two different slopes, implicating two different activated conduction in low $\mathrm{I}_{2}$ doped Co(dtc-SB) NWs. The slope of the curve near $300 \mathrm{~K}$ is higher compared to slope at $425 \mathrm{~K}$ region. A similar behaviour is observed in high $\mathrm{I}_{2}$ doped sample. The $\mathrm{R}$ of the sample at room temperature is observed to be $\sim 60 \mathrm{kohm}(\sigma \sim 1.4 \mathrm{E}-5$ $\left.\mathrm{Scm}^{-1}\right)$ which decreases to $7 \mathrm{kohm}\left(\sigma \sim 0.12 \mathrm{mScm}^{-1}\right)$ at $400 \mathrm{~K}$. The decrease in resistance is attributed to high level doping (Guijarro et al, 2010; Heeger, 2001). Fig. c inset shows the R-T behaviour for $n$-doped (Na) $\mathrm{Co}(\mathrm{dtc}-\mathrm{SB}) \mathrm{NWs}$ which is apparently similar to p-doped sample. The resistance is $3 \mathrm{Mohm}$ at $300 \mathrm{~K}$ which is decreased to $200 \mathrm{kohm}$ at $430 \mathrm{~K}$. The $\log \mathrm{R}$ vs $1 / \mathrm{T}$ plot exhibits two different slopes analogous to $\mathrm{I}_{2}$ doped $\mathrm{Co}(\mathrm{dtc}-\mathrm{SB}) \mathrm{NWs}$. In this case, the slope near to the room temperature is less
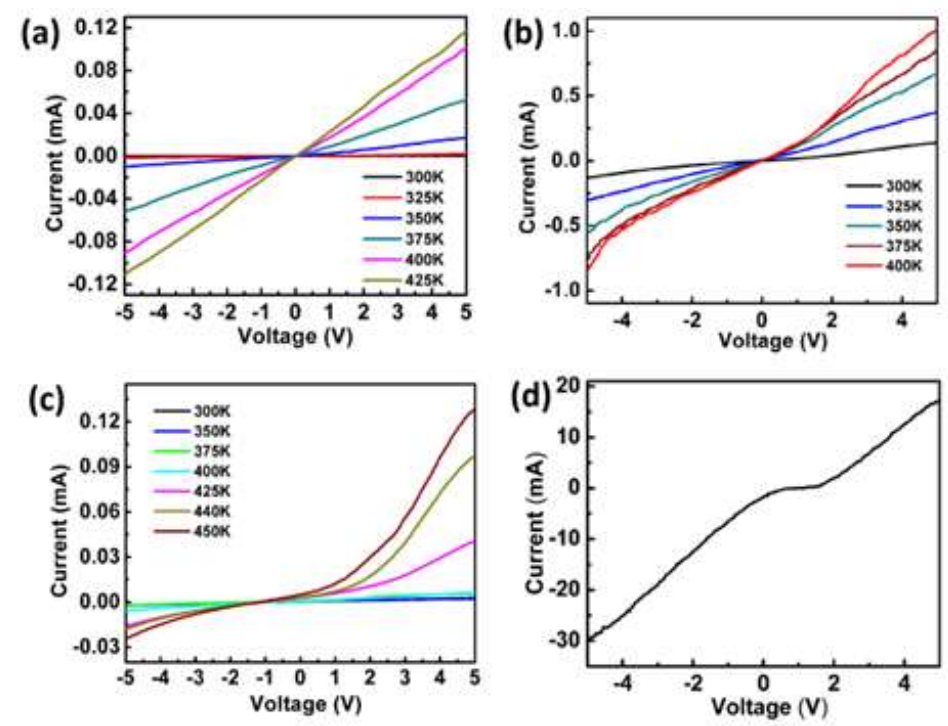

Figure 7. Current-Voltage curve of $I_{2}$ and Na doped Cobalt complex: (a) Low $I_{2}$ doped (9.8 wt.\%) Co(dtc-SB) shows linear response.(b) At high $\mathrm{I}_{2}$ doping $(20.2 \mathrm{wt} . \%) \mathrm{I}-\mathrm{V}$ response becomes non-linear. (c) Co(dtc-SB) doped with $\mathrm{Na}(5.4 \mathrm{wt} . \%)$ shows asymmetric I-V response. (d) At higher Na doping (11.5 wt.\%) the charge blockade is observed at low voltages.
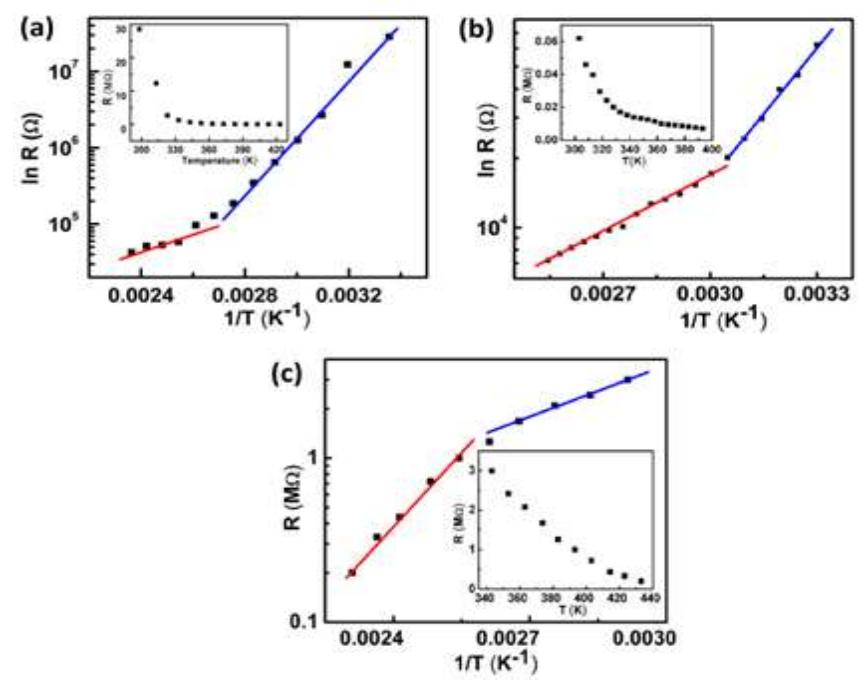

Figure 8. Plots of $\ln R$ vs $1 / T$. Inset shows R-T curve for $I_{2}$ and Na doped Co(dtc-SB): (a) Low $I_{2}$ doped complex, two different slopes are observed. (b) High $\mathrm{I}_{2}$ doping shows similar behaviour. (c) Low Na doped complex also two different slopes are observed. 
steep compared to slope at high temperature. Doped Co(dtc-SB) NWs indicate a conduction mechanism by the combination of two activated conductions $\rho(\mathrm{T})=\rho_{1} \exp \left(\mathrm{E}_{1} / \mathrm{kT}\right)$ and $\rho(\mathrm{T})=\rho_{2} \exp \left(\mathrm{E}_{2} / \mathrm{kT}\right)$ with varying activation energies $E_{1}$ and $E_{2}$. The activation energy is calculated from the slope of the $\ln R$ vs $1 / T$ plot. For room temperature regime, the activation energy for low $\mathrm{I}_{2}$ doped Co(dtc-SB) NWs is $680 \mathrm{meV}$ which decreases to 140 $\mathrm{meV}$ at high temperatures. Slope of the conductivity changes widely depending upon the dopant concentration, microstructure of the sample and backbone of the structure. We hypothesize that the doping with $\mathrm{I}_{2}$ or Na creates a dopant level which is responsible for second activation. The activated transport due to doping is multistep hopping mechanism where charge hops along ligand backbone as illustrated in Fig. 9.

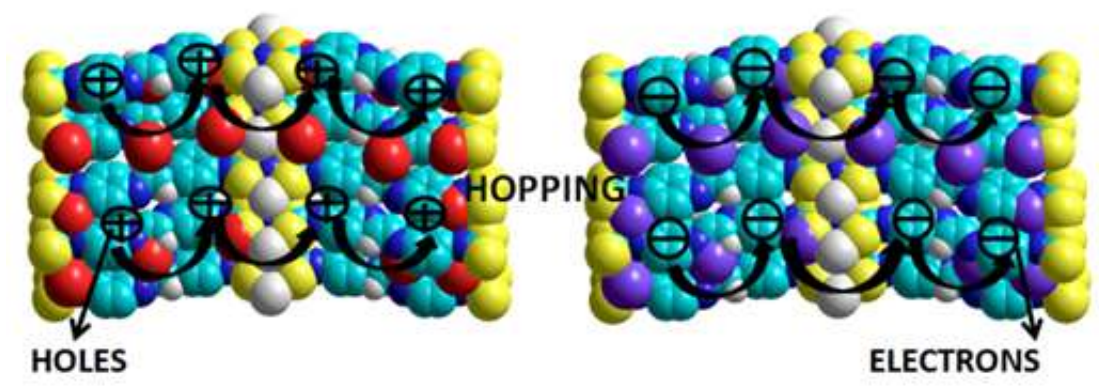

Figure 9. Schematic illustration of the hopping process in (a) Hole conduction in Iodine ( $\left.\mathrm{I}_{3}{ }^{-} / \mathrm{I}_{5}{ }^{-}\right)$(red balls) doped $\mathrm{Co}(\mathrm{dtc}-\mathrm{SB})$ and (b) Electronic conduction in Sodium (purple balls) doped Co(dtc-SB).

A lower activation energy $370 \mathrm{meV}$ is observed in room temperature regime for high $\mathrm{I}_{2}$ doped Co(dtc-SB) NWs which is expected. In high temperature regime, the activation energy for high $\mathrm{I}_{2}$ doped sample $(160 \mathrm{meV})$ is approximately same as for low $\mathrm{I}_{2}$ doped sample. It is evident from these observations that the activation energy in room temperature regime appears due to dopant ions. At high doping level, we observed relatively lower activation energy. As the temperature is increased, complex itself started contributing in conduction. Both low doped and high $\mathrm{I}_{2}$ doped samples exhibit nearly same activation energy. At elevated temperature, polymer itself contributes in charge conduction due to onset of molecular motion. The Na doped Co(dtc-SB) NWs exhibits similar behavior. The activation energy in room temperature regime is $590 \mathrm{meV}$ which decreases to $210 \mathrm{meV}$ at high temperature. As evident from the I-V characteristics, $I_{2}$ doped Co(dtc-SB) NWs exhibit ohmic behaviour whereas I-V characteristics of Na doped Co(dtc-SB) NWs showed asymmetry and rectification. This difference in electrical properties arises from the dopant size (Bantikassegn, \& Inganas, 1996). This small ion discrimination occurs in spite of the fact that these Co(dtc-SB) NWs are amorphous and do not possess well-defined channels as observed in crystalline metal-organic frameworks(MOFs). This implies that although NWs are amorphous, there must be some disordered pore structure as evident in metallo-salen ligand Zn(AFSL) amorphous ICP particles (Nishiyabu et al., 2009). Small $\mathrm{Na}^{+}$ion moves into and out of such disordered pores in nanowires matrix during oxidation/reduction cycles. This gives rise to rectification behaviour while no such detectable difference occurs in the sample having $\mathrm{I}_{3}{ }^{-}$as counter ions. In summary of these results, it can be concluded that small ions are easily transported through ICP pores, while the polymeric anions $\mathrm{I}_{3}{ }^{-}$are not at all mobile. This may be attributed for the major difference in I-V characteristics observed. This leads to the foundation of the proposed mechanism for charge transport in doped ICPs. However, further investigation is necessary to verify the mechanism.

\section{Conclusion}

A diimine containing dithiocarbamate ligand (dtc-SB) is synthesized by a simple and effective condensation process and utilized as building block for multi-functional coordination polymer nanowires by precipitation/coordination polymerization to form Co(dtc-SB) NWs. Structural analysis confirm that nanowires are formed by uniform $\pi-\pi$ stacking of Co(dtc-SB). Presence of pair of satellites in Co $2 p$ XPS spectrum and the binding energy difference $(\Delta \mathrm{E})$ of $15 \mathrm{eV}$ between Co $2 \mathrm{p}_{1 / 2}$ and Co $2 \mathrm{p}_{3 / 2}$ indicate the presence of hexa coordinated $\mathrm{Co}(\mathrm{II})$ in $\mathrm{Co}(\mathrm{dtc}-\mathrm{SB}) \mathrm{NWs}$. Furthermore, hyperfine splitting pattern and ' $\mathrm{g}$ ' parameters in liquid $\mathrm{N}_{2}$ EPR spectrum confirms high spin octahedral coordination environment of $\mathrm{Co}^{2+}$ with two dithiocarbamate ligands coordinated in bidentate mode and axial positions are occupied by two $\mathrm{H}_{2} \mathrm{O}$ molecules in cis configuration. The $\mathrm{Co}$ (dtc-SB) NWs show decrement in optical band gap when doped with iodine and sodium. They are fluorescent and show stoke shift of $75 \mathrm{~nm}$ when excited at $380 \mathrm{~nm}$ while $\mathrm{I}_{2}$ and $\mathrm{Na}$ doped sample show stoke shift of 146 and $86 \mathrm{~nm}$ respectively. The remarkable change in stoke shift and efficient quenching of emission in doped samples may be attributed to the efficient energy transfer from polymeric iodine dopant $\left(\mathrm{I}_{3}^{-} / \mathrm{I}_{5}^{-}\right) / \mathrm{Na}^{+}$to 
the nanowires. Electrical characterisation of $\mathrm{Na} / \mathrm{I}_{2}$ doped $\mathrm{Co}(\mathrm{dtc}-\mathrm{SB}) \mathrm{NWs}$ show conductivity of the order of 3 $\mathrm{mS} / \mathrm{cm}$. The conductivity of the doped nanowires follow doubly activated behaviour with continuous increase with increasing temperature confirming their semiconducting nature. Therefore, these bi-functional $\mathrm{Co}(\mathrm{dtc}-\mathrm{SB})$ NWs will create potentially versatile platform for generating electronic and photoactive devices.

\section{Acknowledgements}

Authors gratefully acknowledge the financial support received from Department of Science and Technology, (DST) New Delhi Grant No. SR/S1/PC-31/2010. Authors thank USIC, DU for characterisation facility. SK Ujjain gratefully thanks DST INSPIRE fellowship for PhD program. Dr. Shashank Shekhar's expert advice and support is thankfully acknowledged.

\section{References}

Atzei, D., Rossi, A., \& Sadun, C. (2000). Synthesis and characterization of a cobalt(III) complex with 1-(D-3-mercapto-2-methylpropionyl)-L-proline Spectrochim. Acta A, 56, 1875-1886. http://dx.doi.org/10.1016/S1386-1425(00)00246-8

Baba, H., \& Nakano, M. (2012). Magnetic and spectroscopic characterizations of high-spin cobalt(II) complex with soft-scorpionate ligand. Inorganic Chemistry Communications, 17, 177-179. http://dx.doi.org/10.1016/j.inoche.2012.01.003

Bantikassegn, W., \& Inganas, O. (1996). The electrical properties of junctions between aluminium and doped polypyrrole. Journal of Physics D: Applied Physics, 29, 2971-2975. http://dx.doi.org/10.1088/0022-3727/29/12/005

Battistoni, C., Gastaldi, L., Mattogno, G., Simeone, M.G., \& Viticoli, S. (1987). Structural and magnetic properties of layer compounds: CoGaInS 4 . Solid State Communications, 61, 43-46. http://dx.doi.org/10.1016/0038-1098(87)90011-1

Bryce, M. R. (1991). Recent progress on conducting organic charge-transfer salts. Chemical Society Review, 20, 355-390. http://dx.doi.org/10.1039/CS9912000355

Bryce, M. R. (1995). Current trends in tetrathiafulvalene chemistry: towards increased dimensionality. Journal of Material Chemistry, 5, 1481-1496. http://dx.doi.org/10.1039/JM 9950501481

Champness, N. R. (2009). Coordination Polymers: From Metal-Organic Frameworks to Spheres. Angewandte Chemie International Edition, 48, 2274-2275. http://dx.doi.org/10.1002/anie. 200806069

Cho, W., Lee, Y. J., Lee, H. J., \& Oh, M. (2009). Systematic transformation of coordination polymer particles to hollow and non-hollow $\mathrm{In}_{2} \mathrm{O}_{3}$ with pre-defined morphology. Chemical Communication, 4756-4758. http://dx.doi.org/10.1039/ B907281K

Collman, J. P., McDevitt, J. T., Yee, G. T., Leidner, C. R., McCullough, L. G., Little, W. A., \& Torrance, J. B. (1986). Conductive polymers derived from iron, ruthenium, and osmium metalloporphyrins: The shish-kebab approach. PNAS Proceedings of the National Academy of Sciences, 83, 4581-4585. http://www.pnas.org/ content/83/13/4581.short

Cookson, J., \& Beer, P. D. (2007). Exploiting the dithiocarbamate ligand in metal- directed self-assembly. Dalton Transactions, 1459-1472. http://dx.doi.org/10.1039/ B618088D

Coronado, E., Mascaros, J. R. G., Capilla, M. M., Martinez, J. G., \& Pardo-Ibanez, P. (2007). Bistable Spin-Crossover Nanoparticles Showing Magnetic Thermal Hysteresis near Room Temperature. Advanced Materials, 19, 1359-1361. http://dx.doi.org/ 10.1002/adma.200700559

Dai, L. (1992). Charge-transfer complexes between polyacetylene-type polymers and iodine in solution. Journal of Physical Chemistry, 96, 6469-6471. http://dx.doi.org/10.1021/ j100194a067

Dhawan, S. K., \& Trivedi, D. C. (1992). Synthesis and properties of polyaniline obtained using sulphamic acid. Journal of Applied Electrochemistry, 22, 563-570. http://dx.doi.org/10.1007/BF01024098

Diel, B. N., Inabe, T., Jaggi, N. K., Lyding, J. W., Schneider, O., Hanack, M., Kannewurf, C. R., Marks, T. J., \& Schwartz, L. H. (1984). Cofacial assembly of metallomacrocycles as an approach to controlling lattice architecture in low-dimensional molecular solids. Chemical, structural, oxidation-state, transport, and optical properties of the iron coordination polymer [Fe(phthalocyaninato)(.mu.-pyrazine)]n and the consequences of halogen doping. Journal of the American Chemical Society, 106, 3207-3214. http://dx.doi.org/10.1021/ja00323a024 
Fabretti, A. C., Forghieri, F., Giusti, A., Preti, C., \& Tosi, G. (1984). The syntheses and properties of cobalt(II), nickel(II) and copper(II) complexes with some heterocyclic dithiocarbamates. Inorganica Chimica Acta, 86, 127-131. http://dx.doi.org/10.1016/S0020-1693(00)82333-6

Farha, O. K., Spokoyny, A. M., Mulfort, K. L., Hupp, J. T., Galli, S. \& Mirkin, C. A. (2009). Gas-Sorption Properties of Cobalt(II)-Carborane-Based Coordination Polymers as a Function of Morphology. Small, 5, 1727-1731. http://dx.doi.org/ 10.1002/smll.200900085

Fiorani, D., Gastaldi, L., \& Viticoli, S. (1983). X-ray and spectroscopic investigations on polycrystalline $\mathrm{Co}_{\mathrm{x}} \mathrm{Zn}_{1-\mathrm{x}} \mathrm{In}_{2} \mathrm{~S}_{4} \quad$ solid solution. Solid State Communications, 48, 865-867. http://dx.doi.org/10.1016/0038-1098(83)90135-7

Gaur, J., Jain, S., Bhatia, R., Lal, A., \& Kaushik, N. K. (2013). Synthesis and characterization of a novel copolymer of glyoxal dihydrazone and glyoxal dihydrazone bis(dithiocarbamate) and application in heavy metal ion removal from water. Journal of Thermal Analysis and Calorimetry, 112, 1137-1143. http://dx.doi.org/10.1007/s10973-013-3136-x

Giovagnini, L., Sitran, S., Montopoli, M., Caparrotta, L., Corsini, M., Rosani, C., Zanello, P., Dou, Q. P., \& Fregona, D. (2008). Chemical and Biological Profiles of Novel Copper(II) Complexes Containing S-Donor Ligands for the Treatment of Cancer. Inorganic Chemistry, 47, 6336-6343. http://dx.doi.org/10.1021/ic800404e

Giroud, N., Dorge, S., \& Trouve, G. (2010). Mechanism of thermal decomposition of a pesticide for safety concerns: Case of Mancozeb. Journal of Hazardous Materials, 184, 6-15. http://dx.doi.org/10.1016/j.jhazmat.2010.07.053

Guijarro, A., Castillo, O., Welte, L., Calzolari, A., Sanz Miguel, P. J., Gomez-Garcia, C. J., Olea, D., Felice, R. di., Gomez-Herrero, J., \& Zamora, F. (2010). Conductive Nanostructures of MMX Chains. Advanced Functional Materials, 20, 1451-1457. http://dx.doi.org/ 10.1002/adfm. 200901901

Harding, D. J., Harding, P., Dokmaisrijan, S., \& Adams, H. (2011). Redox-active nickel and cobalt tris(pyrazolyl)borate dithiocarbamatecomplexes: air-stable Co(II) dithiocarbamates. Dalton Transactions, 40, 1313-1321. http://dx.doi.org/10.1039/ C0DT01010C

Heeger, A. J. (2001). Semiconducting and Metallic Polymers: The Fourth Generation of Polymeric Materials (Nobel Lecture). Angewandte Chemie International Edition, 40, 2591-2611. http://dx.doi.org/10.1002/1521-3773(20010716)40:14<2591:: AID-ANIE2591> 3.0.CO;2-0

Heo, J., Jeon, Y. M., \& Mirkin, C. A. (2007). Reversible Interconversion of Homochiral Triangular Macrocycles and Helical Coordination Polymers. Journal of the American Chemical Society, 129, 7712-7713. http://dx.doi.org/10.1021/ja0716812

Hwang, D. K., Oh, M. S., Hwang, J. M., Kim, J. H., \& Im, S. (2008). Hysteresis mechanisms of pentacene thin-film transistors with polymer/oxide bilayer gate dielectrics. Applied Physics Letters, 92, 013304(1-3). http://dx.doi.org/10.1063/ 1.2830329

Imaz, I., Hernando, J., Molina, D. R., \& Maspoch, D. (2009). Metal-Organic Spheres as Functional Systems for Guest Encapsulation. Angewandte Chemie International Edition, 48, 2325-2329. http://dx.doi.org/10.1002/anie. 200804255

Imaz, I., Martínez, M. R., Saletra, W. J., Amabilino, D. B., \& Maspoch, D. (2009). Amino Acid Based Metal-Organic Nanofibers. Journal of the American Chemical Society, 131, 18222-18223. http://dx.doi.org/10.1021/ja908721t

Imaz, I., Maspoch, D., Blanco, C. R., Falcon, P. M. J., Campo, J., \& Molina, D. R. (2008). Valence-Tautomeric Metal-Organic Nanoparticles. Angewandte Chemie International Edition, 47, 1857-1860. http://dx.doi.org/10.1002/anie.200705263

Jeon, Y. M., Armatas, G. S., Heo, J., Kanatzidis, M. G., \& Mirkin, C. A. (2008). Amorphous Infinite Coordination Polymer Microparticles: A New Class of Selective Hydrogen Storage Materials. Advanced Materials, 20, 2105-2110. http://dx.doi.org/ 10.1002/adma.200702605

Jeon, Y. M., Heo, J., \& Mirkin, C. A. (2007). Dynamic Interconversion of Amorphous Microparticles and Crystalline Rods in Salen-Based Homochiral Infinite Coordination Polymers. Journal of the American Chemical Society, 129, 7480-7481. http://dx.doi.org/10.1021/ja071046w

Jung, S., \& Oh, M. (2008). Monitoring Shape Transformation from Nanowires to Nanocubes and 
Size-Controlled Formation of Coordination Polymer Particles. Angewandte Chemie International Edition, 47, 2049-2051. http://dx.doi.org/ 10.1002/anie.200704209

Karlin, K. D., \& Hogarth, G. (2005). Transition Metal Dithiocarbamates: 1978-2003. Progress in Inorganic Chemistry, 53, 71-561. http://dx.doi.org/10.1002/0471725587 .ch2

Kross, R. D., Fassel, V. A., \& Margoshes, M. (1956). The Infrared Spectra of Aromatic Compounds. II. Evidence Concerning the Interaction of $\pi$-Electrons and $\sigma$-Bond Orbitals in C-H Out-of-plane Bending Vibrations. Journal of the American Chemical Society, 78, 1332-1335. http://dx.doi.org/10.1021/ja01588a019

Lu, W., Chui, S. S. Y., Ng, K. M., \& Che, C. M. (2008). A Submicrometer Wire-to-Wheel Metamorphism of Hybrid Tridentate Cyclometalated Platinum(II) Complexes. Angewandte Chemie International Edition, 47, 4568-4572. http://dx.doi.org/10.1002/ anie.200704450

Lu, W., Chui, S. S. Y.,Ng, K. M., \& Che, C. M. (2008). A Submicrometer Wire-to-Wheel Metamorphism of Hybrid Tridentate Cyclometalated Platinum(II) Complexes. Angewandte Chemie International Edition, 47, 4568-4572. http://dx.doi.org/10.1002/ anie.200704450

Luo, J., Lei, T., Wang, L., Ma, Y., Cao, Y., Wang, J., \& Pei, J. (2009). Highly Fluorescent Rigid Supramolecular Polymeric Nanowires Constructed Through Multiple Hydrogen Bonds. Journal of the American Chemical Society, 131, 2076-2077. http://dx.doi.org/10.1021/ja8090774

Mitsumi, M., Murase, T., Kishida, H., Yoshinari, T., Ozawa, Y., Toriumi, K., Sonoyama, T., Kitagawa, H., \& Mitani, T. (2001). Metallic Behavior and Periodical Valence Ordering in a MMX Chain Compound, $\mathrm{Pt}_{2}\left(\mathrm{EtCS}_{2}\right)_{4} \mathrm{I}$. Journal of the American Chemical Society, 123, 11179-11192. http://dx.doi.org/10.1021/ja010900v

Mueller, H., \& Ueba, Y. (1995). A facile synthesis of bis(ethylenedithio)tetrathiafulvalene and related donors for synthetic metals. Synthetic Metals, 70, 1181-1182. http://dx.doi.org/10.1016/0379-6779(94)02811-C

Nishiyabu, R., Aime, C., Gondo, R., Noguchi, T., \& Kimizuka, N. (2009). Confining Molecules within Aqueous Coordination Nanoparticles by Adaptive Molecular Self-Assembly. Angewandte Chemie International Edition, 48, 9465-9468. http://dx.doi.org/10.1002/anie.200904124

Nunez, C., Bastida, R., Lezama, L., Macías, A., Perez-Lourido, P., \& Valencia, L. (2011). Dinuclear Cobalt(II) and Copper(II) Complexes with a $\mathrm{Py}_{2} \mathrm{~N}_{4} \mathrm{~S}_{2}$ Macrocyclic Ligand. Inorganic Chemistry, 50, 5596-5604. http://dx.doi.org/10.1021/ic200287f

Oh, M., \& Mirkin, C. A. (2005). Chemically tailorable colloidal particles from infinite coordination polymers. Nature, 438, 651-654. http://dx.doi.org/10.1038/ nature04191

Pandey, R., Kumar, P., Singh, A. K., Shahid, M., Li, P-Z., Singh, S. K., Xu, Q., Misra, A., \& Pandey, D. S. (2011). Fluorescent Zinc(II) Complex Exhibiting "On-Off-On” Switching Toward $\mathrm{Cu}^{2+}$ and $\mathrm{Ag}^{+}$Ions. Inorganic Chemistry, 50, 3189-3197. http://dx.doi.org/10.1021/ic1018086

Park, K. H., Jang, K., Son, S. U., \& Sweigart, D. A. (2006). Self-Supported Organometallic Rhodium Quinonoid Nanocatalysts for Stereoselective Polymerization of Phenylacetylene. Journal of the American Chemical Society, 128 8740-8741. http://dx.doi.org/10.1021/ja062907o

Pavia, D. L., Lampman, G. L., Kriz, G. S., \& Vyvyan, J. R. (2007). Introduction Of Spectroscopy, Cengage Learning (pp. 22-92).

Peng, A-D., Xiao, D-B., Ma, Y., Yang, W-S., \& Yao, J-N. (2005). Tunable Emission from Doped 1,3,5-Triphenyl-2-pyrazoline Organic Nanoparticles. Advanced Materials, 17, 2070-2073. http://dx.doi.org/10.1002/adma.200401989

Raja, D. S., Bhuvanesh, N. S. P., \& Natarajan, K. (2012). A novel water soluble ligand bridged cobalt(II) coordination polymer of 2-oxo-1,2-dihydroquinoline-3-carbaldehyde (isonicotinic) hydrazone: evaluation of the DNA binding, protein interaction, radical scavenging and anticancer activity. Dalton Transactions, 41, 4365-4377. http://dx.doi.org/10.1039/C2DT12274J

Rieter, W. J., Pott, K. M., Taylor, K. M. L., \& Lin, W.B. (2008). Nanoscale Coordination Polymers for Platinum-Based Anticancer Drug Delivery. Journal of the American Chemical Society, 130, 11584-11585. http://dx.doi.org/10.1021/ ja803383k

Rieter, W. J., Taylor, K. M. L., \& Lin, W. (2007). Surface Modification and Functionalization of Nanoscale Metal-Organic Frameworks for Controlled Release and Luminescence Sensing. Journal of the American Chemical Society, 129, 9852-9853. http://dx.doi.org/10.1021/ja073506r 
Rieter, W. J., Taylor, K. M. L., An, H., Lin, W., \& Lin, W. (2006). Nanoscale Metal-Organic Frameworks as Potential Multimodal Contrast Enhancing Agents. Journal of the American Chemical Society, 128, 9024-9025. http://dx.doi.org/10.1021/ ja0627444

Sreedaran, S., Bharathi, K. S., Rahiman, A. K., Jagadish, L., Kaviyarasan, V., \& Narayanan, V. (2008). Novel unsymmetrical macrocyclic dicompartmental binuclear copper(II) complexes bearing 4- and 6-coordination sites: Electrochemical, magnetic, catalytic and antimicrobial studies. Polyhedron, 27, 2931-2938. http://dx.doi.org/ 10.1016/j.poly.2008.06.025

Sun, X., Dong, S., \& Wang, E. (2005). Coordination-Induced Formation of Submicrometer-Scale, Monodisperse, Spherical Colloids of Organic-Inorganic Hybrid Materials at Room Temperature. Journal of the American Chemical Society, 127, 13102-13103. http://dx.doi.org/10.1021/ja0534809

Tabata, H., Tokoyama, H., Yamakado, H., \& Okuno, T. (2012). Preparation and properties of two-legged ladder polymers based on polydiacetylenes. Journal of Material Chemistry, 22, 115-122. http://dx.doi.org/10.1039/C1JM13896K

Tanaka, D., Henke, A., Albrecht, K., Moeller, M., Nakagawa, K., Kitagawa, S., Groll, J. (2010). Rapid preparation of flexible porous coordination polymer nanocrystals with accelerated guest adsorption kinetics. Nature Chemistry, 2, 410-416. http://dx.doi.org/10.1038/NCHEM.627

Taylor, K. M. L., Jin, A., \& Lin, W. (2008). Surfactant-Assisted Synthesis of Nanoscale Gadolinium MetalOrganic Frameworks for Potential Multimodal Imaging. Angewandte Chemie International Edition, 47, 7722-7725. http://dx.doi.org/10.1002/ anie.200802911

West, D. X., Stark, A. M., Bain, G. A., \& Leberta, A. E. (1996). Copper(II) complexes of 2-formyl-, 6-methyl-2-formyl-

and

2-benzoylpyridineN(4)-(2-methylpyridinyl)-,N(4)-(2-ethylpyridinyl)-and N(4)-methyl(2-ethylpyridinyl)-thi osemicarbazones. Transition Metal Chemistry, 21, 289-295. http://dx.doi.org/ 10.1007/BF00139020

Wohlgemuth, S.-A., White, R. J., Willinger, M.-G., Titirici, M. -M., \& Antonietti, M. (2012). A one-pot hydrothermal synthesis of tunable dual heteroatom-doped carbon microspheres. Green Chemistry, 14, 1515-1523. http://dx.doi.org/10.1039/ C2GC16415A

Wrochem, F. V., Gao, D., Scholz, F., Nothofer, H. G., Nelles, G., \& Wessels, J. M. (2010). Efficient electronic coupling and improved stability with dithiocarbamate-based molecular junctions. Nature Nanotechnology, 5, 618-624. http://dx.doi.org/ 10.1038/nnano.2010.119

Yang, D. -Q., Sun, Y., Guo, Y., \& Da, D. -A. (1999). X-ray photoelectron spectroscopy of nickel dithiolene complex Langmuir-Blodgett films. Applied Surface Science, 148, 196-204. http://dx.doi.org/10.1016/S0169-4332(99)00145-2

Zakirov, A. S., Yuldashev, S. U., Wang, H. J., Lee, J. C., Kang, T. W., \& Mamadalimov, A. T. (2011). Study on electrical transport and photoconductivity in iodine-doped cellulose fibers. Journal of Materials Science, 46, 896-901. http://dx.doi.org/10.1007/s10853-010-4832-6

Zhang, Z., Chen, K., \& Loh, K.P. (2009). Coordination-Assisted Assembly of 1-D Nanostructured Light-Harvesting Antenna. Journal of the American Chemical Society, 131, 7210-7211. http://dx.doi.org/10.1021/ja901041d

Zhao, Y., Zhang, J., Han, B., Song, J., Li, J., \& Wang, Q. (2011). Metal-Organic Framework Nanospheres with Well-Ordered Mesopores Synthesized in an Ionic Liquid/ $\mathrm{CO}_{2} /$ Surfactant System. Angewandte Chemie International Edition, 50, 636-639. http://dx.doi.org/10.1002/anie.201005314

\section{Copyrights}

Copyright for this article is retained by the author(s), with first publication rights granted to the journal.

This is an open-access article distributed under the terms and conditions of the Creative Commons Attribution license (http://creativecommons.org/licenses/by/3.0/). 